(C) 2017 Elsevier Inc. This manuscript version is made available under the CC-BY-NC-ND 4.0 license http://creativecommons.org/licenses/by-nc-nd/4.0/

\title{
ESTIMATING THE ELASTICITY OF INTERTEMPORAL SUBSTITUTION WITH LEVERAGE
}

\author{
Ana González-Urteaga \\ Universidad Pública de Navarra \\ Gonzalo Rubio \\ Universidad CEU Cardenal Herrera
}

\begin{abstract}
Following the recent literature on intermediary asset pricing models, this paper argues that the marginal utility of wealth of financial intermediaries can be used to generate enough volatility and counter-cyclicality on the recursive preference-based stochastic discount factor. Hence, a dynamic econometric strategy of an asset pricing model with the market portfolio return and the leverage growth of financial intermediaries allows for a sensible economic estimate of the elasticity of intertemporal substitution. On the contrary, the same framework with alternative measures of consumption produces extremely poor economic results.
\end{abstract}

This version: March 3, 2017

Keywords: elasticity of intertemporal substitution; leverage; consumption; recursive preferences; dynamic estimation.

JEL classification: C22, E21, G10, G12, G20

We thank Belén Nieto, and two anonymous referees for helpful comments and suggestions. The authors acknowledge financial support from the Ministry of Economics and Competitiveness through grant ECO2015-67035-P. In addition, Gonzalo Rubio acknowledges financial support from Generalitat Valenciana grant PROMETEOII/2013/015 and from the Bank of Spain, and Ana González-Urteaga acknowledges financial support from the Ministry of Economics and Competitiveness through grant ECO2016-77631-R (AEI/FEDER,UE).

Corresponding author: Gonzalo Rubio, Universidad CEU Cardenal Herrera, Reyes Católicos 19, Elche, 03204 Alicante, Spain. Phone: 0-34 965426486 (gonzalo.rubio@uch.ceu.es). 


\section{Introduction}

The elasticity of the intertemporal substitution (EIS hereafter) is one of the key preference parameters of investors' intertemporal investment decisions. However, its estimation remains controversial. There is no consensus on whether it is significantly different from one or, even whether it is significantly above zero. The theoretical and empirical approaches have put either the representative consumer or the representative stockholder consumer as the center of the discussion and estimation.

Our paper steps away from the traditional use of the average households to measuring a financial intermediary stochastic discount factor (SDF hereafter). In particular, we link the SDF pricing framework with the funding capacity of financial intermediaries. To motivate our estimation strategy of the EIS, note that Muir (2014) argues convincingly that the expected market risk premium rises substantially in financial crises, but relatively less in economic recessions or wars. Aggregate consumption growth shows precisely the opposite behavior. This is consistent with the importance of wealth of financial intermediaries for asset prices. Adrian et al. (2014) argue that the marginal utility of the wealth of financial intermediaries is a more informative SDF than the marginal utility of consumption of the representative household. These authors show that a one-factor model based on shocks to the leverage of security broker-dealers prices significantly the cross-section of size, book-to-market, momentum, and bond portfolios. The performance of this new single-factor model presents similar performance to that of the traditional multi-factor models. Our results should be understood in this context. Therefore, we suggest that the estimation of the EIS using leverage may be a reasonable approach to better capture the behavior of timevarying expected returns, and the estimation of preference parameters implicitly related 
to that behavior. Our argument is that the representative intermediary investor should be the focus on the estimation of the EIS.

Throughout the paper, we assume that the representative economic agents, either the average household or the average financial intermediary, have recursive preferences as suggested by Epstein \& Zin $(1989,1991)$. This is particularly useful because this setup breaks the link between risk aversion and the EIS. It is not clear, however, that the Epstein-Zin framework provides enough structure to incorporate an explicit dependency of the equilibrium price of risk on leverage, which is the proxy for the marginal utility of wealth of financial intermediaries. As we explicitly recognize later in the paper, our estimation strategy implicitly assumes that the variances of consumption growth, market portfolio return, and leverage growth are affine functions of leverage. And this is precisely because the equilibrium prices of risk depend on leverage. To justify this approach, we can think of an intertemporal capital asset pricing model (ICAPM) context within the discrete-time approximation of Campbell $(1993,1996)$ under the Epstein \& Zin $(1989,1991)$ preference framework. Note that, in this context, we cannot replace the consumption growth rate by any variable. First, the state variable we employ must forecast the first or second moments of aggregate stock returns (the investment opportunity set). Second, if a given state variable forecasts positive expected aggregate returns, its innovation (the risk factor) should earn a positive risk premium. Indeed, leverage of financial intermediaries satisfy the two conditions that must characterize any state variable within an ICAPM framework. Leverage forecasts market excess returns, and innovations in financial intermediary endogenously reflect changes in underlying economic state variables. In addition, we also know that the risk premium associated with the innovations in leverage is positive and statistically different from zero. 
A complementary additional way to justify this implicit assumption is to think of the structural dynamic models of corporate finance. In particular, Bhamra et al. (2010 a) embed a structural model of credit risk within a dynamic consumption-based pricing model with Epstein-Zin recursive preferences. They employ a business cycle mechanism with an intertemporal macroeconomic risk to generate a common factor pricing both stock returns and corporate bonds. Their approach shows that consumption and stock market volatilities co-move with credit spreads and contributes solving both the equity risk premium and the credit spread puzzles. The Epstein-Zin preferences play a key role since the representative agent in their model must prefer uncertainty to be resolved sooner than later. In a related paper, Bhamra et al. (2010 b) employ the same framework to study the time-varying behavior of capital structure, and show that leverage accounts for most of the macroeconomic risk for predicting corporate debt defaults. These papers are at least consistent with the implicit assumption employed in our estimation strategy about the dependency of consumption growth and market return on leverage.

The main contribution of this paper is to estimate the EIS using a proxy for the marginal utility wealth of financial intermediaries rather than a proxy for the marginal utility of consumption of the representative household. We substitute consumption out from the model to employ, instead, the growth of leverage of financial intermediaries. Using a dynamic asset pricing estimation strategy and the recursive preference framework, we find an estimate of the EIS, which is significantly different from zero. In particular, the estimate of the EIS is 0.943. On the other hand, when we employ different consumption-based alternatives, the results are inconsistent with a sensible and economically valid interpretation. 
This paper proceeds as follows. Section 2 briefly describes the related literature and the available empirical evidence regarding the estimation of the EIS. Section 3 describes the data and Section 4 discusses the econometric approach. Then, Section 5 reports the empirical findings. Finally, Section 6 presents our conclusions.

\section{Related Literature and Available Empirical Evidence}

To explain the time-varying behavior of expected return, macro-finance asset pricing models incorporate a SDF that extend the basic power utility model with an extra (unobservable) variable $X$ that varies over time, and more importantly that makes the SDF to be volatile and counter-cyclical:

$$
M_{t+1}=\rho\left(\frac{C_{t+1}}{C_{t}}\right)^{-\gamma} X_{t+1}
$$

where $M_{t+1}$ is the SDF, $\rho$ is the subjective discount factor that captures impatience, $C_{t+1}$ denotes aggregate consumption, $\gamma$ is the coefficient of relative risk aversion, and $X_{t+1}$ is the recession variable; this is to say, the variable that changes over recessions. ${ }^{1}$ Under alternative specification of $X$, we obtain, among others, the habitbased model of Campbell \& Cochrane (1999), the recursive preference framework of Epstein \& Zin $(1989,1991)$, the long run risk model (with recursive utility) of Bansal \& Yaron (2004), and Hansen et al. (2008), the idiosyncratic risk model of Constantinides \& Duffie (1996) or the heterogeneous preference model of Garleanu \& Panageas (2015). ${ }^{2}$ The idea is always the same. In addition to consumption, investors are afraid of a state variable that covaries positively with asset returns.

In these macro-finance models, relevant preference parameters are risk aversion, which capture the investor's reluctance to substitute consumption across states of

\footnotetext{
${ }^{1}$ See Cochrane $(2007,2016)$, and Campbell (2003) for detailed reviews of these ideas.

${ }^{2}$ Ghosh et al. (2017) present a nonparametric estimation of the unobservable component of equation (1).
} 
nature, and the EIS describing the aversion to substitute consumption over time. Epstein \& Zin $(1989,1991)$ employ the theoretical recursive preference framework of Kreps \& Porteus (1978) to break the link between risk aversion and the EIS. ${ }^{3}$ For this reason, this utility framework has been extensively used to estimate the EIS.

The recursive utility specification employs a nonlinear aggregator to combine present and future utility,

$$
U_{t}=\left[(1-\rho) C_{t}^{1-\kappa}+\rho\left[E_{t}\left(U_{t+1}^{1-\gamma}\right)\right]^{\frac{1-\kappa}{1-\gamma}}\right]^{\frac{1}{1-\kappa}},
$$

where $\kappa$ is the inverse of the EIS, denoted by $\psi$, or $\kappa=1 / \psi$. In this case, it can be shown that equation (1) becomes

$$
M_{t+1}=\rho\left(\frac{C_{t+1}}{C_{t}}\right)^{-\kappa}\left(X_{t+1}\right)^{\kappa-\gamma}=\rho\left(\frac{C_{t+1}}{C_{t}}\right)^{-\kappa}\left(\frac{U_{t+1}}{\left[E_{t}\left(U_{t+1}^{1-\gamma}\right)\right] 1 / 1-\gamma}\right)^{\kappa-\gamma}
$$

Epstein \& Zin $(1989,1991)$ employ this framework, together, with the intertemporal budget constraint for the representative consumer, to obtain a SDF, which approximates the continuation value of the future consumption plan or, more generally, the recession state variable $X$

$$
M_{t+1}=\left[\rho\left(\frac{C_{t+1}}{C_{t}}\right)^{-\kappa}\right]^{\theta}\left[\frac{1}{R_{m t+1}}\right]^{1-\theta},
$$

where $R_{m t+1}$ is the return on aggregate wealth, and $\theta \equiv(1-\gamma) /(1-\kappa)$.

Under the traditional power utility function, the SDF is a special case of (4) for $\theta=1$. By assuming jointly lognormal, and homoskedastic returns and consumption growth, the first order Euler equation becomes

\footnotetext{
${ }^{3}$ Note that the habit-based model also distinguishes between risk aversion and the EIS. However, in practice the model offsets the time-varying intertemporal demands with a time-varying precautionary savings, which makes unfeasible the direct estimation of the elasticity parameter.
} 


$$
\Delta c_{t+1}=\mu_{j}+\psi r_{j t+1}+\varepsilon_{j t+1}
$$

where the constant intercept is given by $\mu_{j}=\psi \ln \rho+\frac{\psi}{2} \sigma_{j}^{2}$, $\sigma_{j}^{2}=\operatorname{Var}\left(r_{j t+1}-\psi^{-1} \Delta c_{t+1}\right), \quad \gamma \equiv \psi^{-1}, \quad c_{t+1} \equiv \ln \left(C_{t+1}\right), \quad r_{j t+1} \equiv \ln \left(R_{j t+1}\right), \quad$ and $R_{j t+1}$ is the rate of return of any asset $j$. Initial research estimating the EIS employs alternative variants of expression (5) using, therefore, a power utility framework. Hansen \& Singleton (1983), followed by Campbell \& Mankiw (1989, 1991), using nondurable consumption growth and an instrumental variable regression methodology, estimate values of the EIS close to zero and below 0.4, which suggests that $\psi$ is small. Ogaki \& Reinhart (1998) modify the power utility model to introduce nonseparable preferences between nondurable and durable consumption, and they employ data on nondurable, nondurable plus services, and durable goods. Overall, the EIS estimator tends to be small, different from zero, and higher when they recognize nonseparability. In particular, an important finding is that the intratemporal elasticity between nondurable and durable goods is higher than the EIS. However, the results are mixed when they employ nondurable goods and services and durable goods.

More recent papers employ the recursive preference framework given by equations (2), (3), and (4). Yogo (2004) reaches similar conclusions regarding the low value of the EIS. He employs nondurable goods and services from the U.S. and total consumption for ten additional countries, and he concludes that a reasonable value of the EIS for the U.S. market is as low as 0.2. This evidence implies that, after all, the insight of recursive utility allowing for $\psi$ being large even when $\gamma$ is large, may not have strong implications for the understanding of time-varying expected returns.

However, alternative approaches have argued that estimates of the EIS, even under the recursive preference framework, may be biased due to aggregation and limited 
participation issues on the one hand, and time-varying volatility and precautionary savings on the other. First of all, Vissing-Jorgensen (2002) employs micro data from the U.S. Consumer Expenditure Survey to introduce explicitly limited stock market participation in the estimation approach of the EIS. Using stockholder consumption data, this author finds estimates of the EIS between 0.3 and 0.4 for stockholders, and around 0.8 to 1.0 for bondholders. The idea of this approach is that the consumptionbased Euler equation cannot be expected to hold for households that do not maintain positions on stocks. This is similar to the argument we employ to justify our estimation of the EIS with the growth of leverage of financial intermediaries. Vissing-Jorgensen \& Attanasio (2003) also employ stockholder consumption growth, but they argue that market wealth is a combination of financial wealth, which is a portfolio of stocks and bonds, and human capital. According to their results, these authors argue that the EIS is likely to be above $1 .^{4}$

Secondly, Bansal \& Yaron (2004), and Bansal et al. (2009) point out that the estimates of the EIS are based on loglinear approximations of the consumption-based model, which bias downward the estimate of the EIS when volatility is stochastic. Indeed, Gomes \& Ribeiro (2015) employ a loglinearized version of the first order Euler equation, under the SDF given by (4), which recognizes both time-varying volatility, and precautionary savings:

$$
\Delta c_{t+1}=\psi \ln \rho+\frac{\psi(\theta-1)}{\theta} r_{m t+1}+\frac{\psi}{\theta} r_{j t+1}+\frac{\psi}{2 \theta} \sigma_{j t}^{2}+\varepsilon_{j t+1},
$$

where $\quad r_{m t+1} \equiv \ln \left(R_{m t+1}\right), \quad$ and $\quad \sigma_{j t}^{2}$ is the conditional variance of $(\theta-1) r_{m t+1}+r_{j t+1}-(\theta / \psi) \Delta c_{t+1}$. Using alternative generalized method of moment

\footnotetext{
${ }^{4}$ Guvenen (2006) argues that limited participation creates substantial wealth inequality in the U.S. Since consumption is more evenly distributed across households than is wealth, the use of aggregate consumption data explains the low value of the EIS. On the other hand, aggregate variables more directly linked to wealth may uncover higher EIS estimators.
} 
specifications and a multivariate approach to estimate the components of $\sigma_{j t}^{2}$, the authors find that the EIS estimates range from 0.4 to 1.8 , while the risk aversion coefficient varies from 0.6 to $2.2 .^{5}$

It is true that this lack of consensus does not require necessarily an alternative SDF. ${ }^{6}$ However, as we already argued in the introduction, it is also true that an alternative SDF and different estimation strategies in which consumption does not played the center role, on either the theoretical or the econometric approaches, may clarify the magnitude of the EIS. To the best of our knowledge this is the first research on the estimation of the EIS with the marginal utility of wealth of financial intermediaries. We next discuss the estimation of the EIS using a dynamic asset pricing estimation context, and the leverage growth of financial intermediaries as the relevant state variable driving asset returns.

\section{Data}

The estimation of the EIS employs quarterly rates of returns of 40 portfolios as test assets. These are four sets of 10 portfolios sorted by size, book-to-market, momentum, and quality. The first three sets are quarterly returns obtained from the monthly data available in Kenneth French's website (http://mba.tuck.darmouth.edu). The market portfolio return and the risk-free rate are also downloaded from French's website. In addition, we employ a fourth set of 10 quality-sorted portfolios obtained from the AQR Capital Management Database (www.aqr.com). The construction of these data follow the suggestion of Asnes et al. (2014), who define a quality stock as the

\footnotetext{
${ }^{5}$ It is also important to note that under constant variance and $\theta=1$, equation (6) is equal to expression (5). However, as pointed out by Gomes \& Ribeiro (2015), the Epstein and Zin's preferences employ at least two assets, and one of them is the representative consumer optimal portfolio. It seems therefore more appropriate to use the recursive rather than the traditional power utility framework.

6 The omission of precautionary savings (and time-varying volatility), the use of nondurable versus durable goods, and limited participation issues may explain by themselves the lack of consensus.
} 
asset for which an investor is willing to pay a high price. They are stocks that are safe (low required rate of return), profitable (high return on equity), growing (high cash flow growth), and well managed (high dividend payout ratio) everything else equal. Asnes et al. (2014) show that a quality-minus-junk factor, that goes long high-quality stocks and shorts low-quality (junk) stocks, earns significant risk-adjusted returns not only in the U.S. market but also across 24 countries. Real returns are constructed as log of the gross stock returns deflated by the consumer price index.

Regarding macroeconomic variables, we collect quarterly seasonally adjusted aggregate real per capita consumption expenditure of non-durables and services from National Income and Product Accounts (NIPA) given in Table 7.1, available at the Bureau of Economic Analysis.

We also use aggregate per capita stockholder consumption growth rates. Exploiting micro-level household consumption data, Malloy et al. (2011) show that long-run stockholder consumption risk explains the cross-sectional variation in average stock returns better than the aggregate consumption risk obtained from nondurable goods and services. In addition, they report plausible risk aversion estimates. They employ data from the Consumer Expenditure Survey (CEX) for the period March 1982 to November 2004 to extract consumption growth rates for stockholders, the wealthiest third of stockholders, and non-stockholders. To extend their available time period for these series, the authors construct factor-mimicking portfolios by projecting the stockholder consumption growth rate series from March 1982 to November 2004 onto a set of instruments and use the estimated coefficients to obtain a longer time series of instrumented stockholder consumption growth. In this paper, we employ the reported estimated coefficients of Malloy et al. (2011) to obtain a factor-mimicking portfolio with the same set of instruments for stockholder consumption for our sample period. 
A well-known problem with the SDF under power utility is the low volatility of consumption growth relative to stock market data. Most of the necessary volatility generated by any consumption-based SDF must come from the recession variable $X_{t+1}$ given in equation (1). The use of stockholder consumption data is consistent with this reasoning. An additional (and alternative) source of extra volatility may come from time-varying risk aversion. The inverse of the surplus consumption ratio suggested by Campbell \& Cochrane (1999) is closely related to time-varying risk aversion. In order to estimate a time-series of surplus consumption, we employ the external habit preference model of Campbell \& Cochrane (1999) with stochastic discount factor (SDF) given by

$$
M_{t+1}=\rho\left(\frac{S_{t+1}}{S_{t}} \frac{C_{t+1}}{C_{t}}\right)^{-\gamma},
$$

where $\gamma$ is the curvature parameter of the utility function that provides a lower bound on the time-varying coefficient of relative risk aversion, $S_{t}=\left(C_{t}-H_{t}\right) / C_{t}$ is the surplus consumption ratio, $H_{t}$ is the level of habit, and $\gamma / S_{t}$ is the counter-cyclical time-varying risk aversion. ${ }^{7}$ The aggregate consumption follows a random walk and the surplus consumption process is

$$
s_{t+1}=(1-\phi) \bar{s}+\phi s_{t}+\lambda\left(s_{t}\right)\left(c_{t+1}-c_{t}-g\right)
$$

where $g$ is the mean rate of consumption growth, $\phi$ is the persistence of the habit shock, and the response or sensitivity coefficient $\lambda\left(s_{t}\right)$ is given by

$$
\lambda\left(s_{t}\right)=\left(1 / \sigma_{c} \sqrt{\gamma / 1-\phi}\right) \sqrt{1-2\left(s_{t}-\bar{s}\right)}-1
$$

where $\sigma_{c}$ is the volatility of the consumption growth rate and, as in Section 2, lower capital letters denote variables in logarithms. It is important to notice that the empirical

\footnotetext{
${ }^{7}$ Note that in the Campbell \& Cochrane (1999) model, $X_{t+1}=\left(S_{t+1} / S_{t}\right)^{-\gamma}$.
} 
implementation of the model described by equations (7) to (9) estimates the surplus consumption process using an alternative set of test assets to avoid potential confounding effects. In particular, the surplus consumption is estimated using an iterative generalized method of moment procedure with 25 portfolios sorted by size and book-to-market, which also available in French's website. ${ }^{8}$

The leverage factor proposed by Adrian et al. (2014) is the seasonally adjusted log changes in the level of broker-dealer leverage and is available quarterly from 1968 to 2009. Adrian et al. (2014) test four alternative intermediary asset pricing models, employing either book or market values from either broker-dealers or commercial banks as aggregate risk factors. These authors show that the model specification based on broker-dealer book leverage performs relatively well in comparison to other intermediary pricing models. ${ }^{9}$ The period for which these data are available defines our sample estimation period of the EIS.

Table 1 shows the descriptive statistics of the aggregate variables used in the estimation of the EIS. In particular, we display the correlation coefficients between the alternative consumption growth rates, the leverage factor, and the stock market return. The leverage factor has a relatively large correlation coefficient with stockholder consumption growth, and a relatively low correlation with non-durable consumption. Stockholder consumption is highly correlated with the stock market return, and surplus consumption growth is strongly correlated with non-durable consumption growth. The volatility of leverage is even larger than the volatility of the stock market return, and it is much larger than the volatility of any of the consumption volatility measures. As expected, the volatility of both, stockholder consumption and surplus consumption is

\footnotetext{
${ }^{8}$ The persistence parameter, $\phi$, is estimated employing data from the dividend yield available in Robert Shiller's website (http://www.econ.yale.edu/ shiller/), and the optimal estimator of curvature parameter, $\gamma$, turns out to be equal to 2.46 .

9 The quarterly series are available from Tobias Adrian's web page (https://www.newyorkfed.org/research/economists/adrian).
} 
higher than the volatility of non-durable consumption growth. Figure 1 displays the yearly growth rate of the leverage factor and the alternative measures of consumption. Although the overall pattern along the economic cycles is similar with a clear procyclical pattern in all variables, the leverage factor shows sharp declines during economic and financial crisis, which is consistent with the idea that sharp drops in leverage of financial intermediaries captures extremely well bad economic times.

\section{The Econometric Strategy}

Given the SDF of expression (4), the first order condition for any asset or portfolio $p$ is given by

$$
E_{t}\left\{\left[\rho\left(\frac{C_{t+1}}{C_{t}}\right)^{-\kappa}\right]^{\theta} R_{m t+1}^{\theta-1} R_{p t+1}\right\}=1 .
$$

Campbell $(1993,1996)$ shows that the log linear approximation to equation (10) is

$$
E_{t}\left(r_{p t+1}^{e}\right) \cong \theta \kappa \operatorname{Cov}_{t}\left(r_{p t+1}, \Delta c_{t+1}\right)+(1-\theta) \operatorname{Cov}_{t}\left(r_{p t+1}, r_{m t+1}\right),
$$

where $r_{p t+1}^{e}$ is the excess return over the risk-free rate of portfolio $p$. The expected risk premium of any asset or portfolio $p$ is a weighted combination of portfolio's $p$ covariance with consumption growth (scaled by the inverse of the EIS) and portfolio's $p$ covariance with the market. This is the dynamic theoretical log linear approximation we employ in the estimation strategy of the EIS with alternative measures of consumption growth given by the non-durable consumption, stockholder consumption, and surplus consumption.

Since, in this paper we argue that the marginal utility of consumption of the representative consumer may be substituted by the marginal utility of wealth of the representative investor, equation (11) holds for the leverage of the financial 
intermediaries, denoted by $\operatorname{Lev}_{t+1}$, as a proxy for the growth of their marginal utility of wealth,

$$
E_{t}\left(r_{p t+1}^{e}\right) \cong \theta \kappa \operatorname{Cov}_{t}\left(r_{p t+1}, \operatorname{Lev}_{t+1}\right)+(1-\theta) \operatorname{Cov}_{t}\left(r_{p t+1}, r_{m t+1}\right)
$$

Therefore, we estimate the following expression,

$$
E_{t}\left(r_{p t+1}^{e}\right) \cong \theta \kappa \operatorname{Cov}_{t}\left(r_{p t+1}, z_{t+1}\right)+(1-\theta) \operatorname{Cov}_{t}\left(r_{p t+1}, r_{m t+1}\right)
$$

where $z_{t+1}$ denotes either consumption growth, $\Delta c_{t+1}$, or leverage growth, Lev $v_{t+1}$. Note that to estimate the EIS, we can always run regressions of the excess returns of each portfolio in our sample on the covariance between the portfolio return and consumption growth or leverage, and on the covariance between portfolio return and market return. Therefore, from the empirical specification of equation (13), we estimate $\theta \kappa$ and $(1-\theta)$. From them, we get the estimate of $\theta$, the estimate of $\kappa$ and, therefore, the EIS because $\kappa \equiv 1 /$ EIS . Finally, using the expression, $\theta \equiv(1-\gamma) /(1-\kappa)$, and the estimators $\hat{\theta}$ and $\hat{\kappa}$, we obtain an estimate for the coefficient of relative risk aversion since $\hat{\gamma}=1-\hat{\theta}(1-\hat{\kappa})$.

To implement the estimation of expression (13), we follow the dynamic asset pricing model of Adrian et al. (2015), and Adrian et al. (2014). Our particular implementation of this model combines two cross-sectional aggregate risk factors, which are the alternative measures of consumption growth or leverage of financial intermediaries and the market portfolio return, and one predicting factor, which is leverage. ${ }^{10}$ Note that when we employ leverage as the risk factor, leverage plays the role of both the risk factor and the predicting variable. The underlying assumption is that the SDF is linear on the innovations of the risk factors,

\footnotetext{
${ }^{10}$ Both, Adrian et al. (2014), and Muir (2014) show that leverage is a strong predictor of the market excess return.
} 


$$
\frac{M_{t+1}-E_{t}\left(M_{t+1}\right)}{E_{t}\left(M_{t+1}\right)}=-\lambda_{t}^{\prime} \Sigma^{-1 / 2} u_{t+1}
$$

where $u_{t+1}=\left(\begin{array}{c}u_{m t+1} \\ u_{z t+1}\end{array}\right)$ and $u_{m t+1}$ and $u_{z t+1}$ are the innovations of the market portfolio return and the consumption/leverage factor, and $\Sigma$ is the variance-covariance matrix of innovations. These innovations come from the VAR(1) system given by

$$
\left(\begin{array}{c}
r_{m t+1} \\
z_{t+1}
\end{array}\right)=\left(\begin{array}{c}
\mu_{m} \\
\mu_{z}
\end{array}\right)+\left(\begin{array}{cc}
\phi_{m m} & \phi_{m z} \\
\phi_{z m} & \phi_{z z}
\end{array}\right)\left(\begin{array}{c}
r_{m t} \\
z_{t}
\end{array}\right)+\left(\begin{array}{c}
u_{m t+1} \\
u_{z t+1}
\end{array}\right)
$$

Moreover, the prices of risk are affine functions of the predicting factor

$$
\lambda_{t}=\Sigma^{-1 / 2}\left(\lambda_{k}+\lambda_{1} \text { Lev }_{t}\right)
$$

Under this framework, the risk premium of any portfolio is

$$
\begin{aligned}
E_{t}\left(r_{p t+1}^{e}\right) & =-\frac{\operatorname{Cov}_{t}\left(M_{t+1}, r_{p t+1}\right)}{E_{t}\left(M_{t+1}\right)}=\lambda_{t}^{\prime} \Sigma^{-1 / 2} \operatorname{Cov}_{t}\left(u_{t+1}, r_{p t+1}^{e}\right) \\
& =\left(\lambda_{k}+\lambda_{1} \operatorname{Lev}_{t}\right)^{\prime} \Sigma^{-1} \operatorname{Cov}_{t}\left(r_{p t+1}^{e}, z_{t+1}\right)
\end{aligned}
$$

Therefore, expected risk premia are given by

$$
E_{t}\left(r_{p t+1}^{e}\right)=\beta_{p t}^{\prime}\left(\lambda_{k}+\lambda_{1} \operatorname{Lev}_{t}\right)
$$

and

$$
\beta_{p t}=\Sigma^{-1} \operatorname{Cov}_{t}\left(r_{p t+1}^{e}, z_{t+1}\right)
$$

As usual, we may think about realized returns as the sum of expected returns plus return innovations:

$$
r_{p t+1}^{e}=\beta_{p t}^{\prime}\left(\lambda_{k}+\lambda_{1} L e v_{t}\right)+\underbrace{\left\lfloor r_{p t+1}^{e}-E_{t}\left(r_{p, t+1}^{e}\right)\right\rfloor}_{\text {innovations }} .
$$

The return innovations can also be decomposed into a component that is conditionally correlated with the innovations of the risk factors $u_{t+1}$ and a return pricing error 


$$
r_{p t+1}^{e}-E_{t}\left(r_{p t+1}^{e}\right)=\delta_{p t}^{\prime} u_{t+1}+e_{p t+1}
$$

By the definition of beta,

$$
\delta_{p t}=\Sigma^{-1} \operatorname{Cov}_{t}\left(r_{p t+1}^{e}, z_{t+1}\right)=\beta_{p t}
$$

Therefore, the final model to be estimated is given by

$$
r_{p t+1}^{e}=\beta_{p t}^{\prime}\left(\lambda_{k}+\lambda_{1} L e v_{t}\right)+\beta_{p t}^{\prime} u_{t+1}+e_{p t+1}
$$

In words, the excess returns, $r_{p t+1}^{e}$, depend on the expected excess returns, $\beta_{p t}^{\prime}\left(\lambda_{k}+\lambda_{1} L e v_{t}\right)$, the term that is conditionally correlated with the innovations to the risk factors, $\beta_{p t}^{\prime} u_{t+1}$, and a return pricing error that is conditionally orthogonal to the risk factor innovations.

The specific three steps in the estimation of expression (23) are as follows:

(i) We estimate the VAR(1) system by OLS. Hence, we generate two series of factor risk innovations $u_{m t+1}$ and $u_{L e v t+1}\left(u_{\Delta c t+1}\right)$.

(ii) For each portfolio $p$ in the sample, that is to say, for each of the 40 test asset portfolios, we run the predicting rolling regressions using always 27 past quarters plus the contemporaneous quarter ( 7 years of data):

$$
r_{p t+1}^{e}=\lambda_{p k}+\lambda_{p l} L e v_{t}+\beta_{p t}^{\prime} u_{t+1}+\varepsilon_{p t+1}
$$

Therefore, we run portfolio returns on the time series of the lagged predictor factor and the contemporaneous innovations to the two cross sectional risk factors. Hence, for each portfolio, we estimate a time series of predictive slopes and risk factor betas.

(iii) We run cross sectional regression of $\hat{\lambda}_{p k t}$ and $\hat{\lambda}_{p l t}$ on the betas. Therefore, the price of risk parameters or risk premia are obtained by cross sectionally regressing, on each quarter $t$, the constant and the predictive slopes, from the previous time series regressions, on the betas in two separate estimation equations: 


$$
\begin{gathered}
\lambda_{p k t}=\lambda_{0 t}+\lambda_{m t} \beta_{p m t}+\lambda_{z t} \beta_{p z t}+e_{p k t} ; p=1, \ldots, N ; z=\Delta c, \text { Lev } \\
\lambda_{p l t}=\lambda_{01 t}+\lambda_{m, \text { Levt }} \beta_{p m t}+\lambda_{z, \text { Levt }} \beta_{p z t}+e_{p t} ; p=1, \ldots, N ; z=\Delta c, \text { Lev } .
\end{gathered}
$$

Given that for each quarter, we estimate the cross sectional equations (25) and (26), we obtain a time-series of the cross sectional estimators. As in the traditional Fama \& MacBeth (1973) approach, the final estimates are the time series averages of these parameters. We end up estimating six parameters in the cross section:

$$
\Phi^{m, z}=\left\{\lambda_{0}, \lambda_{m}, \lambda_{z}, \lambda_{01}, \lambda_{m, L e v}, \lambda_{z, L e v}\right\},
$$

from the two separate cross sectional regressions (25) and (26). In particular, when we employ the market portfolio return and leverage as the risk factor, the set of parameters is

$$
\Phi^{m, L e v}=\left\{\lambda_{0}, \lambda_{m}, \lambda_{L e v}, \lambda_{01}, \lambda_{m, L e v}, \lambda_{\text {Lev }, \text { Lev }}\right\}
$$

When we employ consumption growth as the risk factor together with the market portfolio return, the set of parameters is

$$
\Phi^{m, C}=\left\{\lambda_{0}, \lambda_{m}, \lambda_{\Delta c}, \lambda_{01}, \lambda_{m, L e v}, \lambda_{\Delta c, \text { Lev }}\right\}
$$

As already mentioned in the introductory section, it is important to recognize that this approach implicitly assumes that the variances of $z_{t+1}$ and $r_{m t+1}$ depend on leverage. To see this, note that we can write equation (13) as

$$
E_{t}\left(r_{p t+1}^{e}\right) \cong \theta \kappa \operatorname{Var}_{t}\left(z_{t+1}\right) \frac{\operatorname{Cov}_{t}\left(r_{p t+1}, z_{t+1}\right)}{\operatorname{Var}_{t}\left(z_{t+1}\right)}+(1-\theta) \operatorname{Var}_{t}\left(r_{m t+1}\right) \frac{\operatorname{Cov}_{t}\left(r_{p t+1}, r_{m t+1}\right)}{\operatorname{Var}_{t}\left(r_{m t+1}\right)}
$$

Then, the corresponding risk premia are given by

$$
\lambda_{z t}=\theta \kappa \operatorname{Var}_{t}\left(z_{t+1}\right)
$$

and

$$
\lambda_{m t}=(1-\theta) \operatorname{Var}_{t}\left(r_{m t+1}\right) .
$$


On other hand, from expression (16), we impose that the prices of risk are affine function of leverage:

$$
\lambda_{t}=\left(\begin{array}{c}
\lambda_{m t} \\
\lambda_{z t}
\end{array}\right)=\left(\begin{array}{c}
\lambda_{m k} \\
\lambda_{z k}
\end{array}\right)+\left(\begin{array}{c}
\lambda_{m 1} \\
\lambda_{z 1}
\end{array}\right) L e v_{t}
$$

Hence, implicitly, the variances of $z_{t+1}$ and $r_{m t+1}$ depend on leverage. Our estimation strategy assumes a consumption-based pricing model with recursive preferences where the equilibrium prices of risk depend on leverage. As we argued in the Introduction, while this is not a direct implication of the model with recursive preference, these assumptions are consistent with an ICAPM in which leverage is the state variable that forecasts future behavior of the opportunity set, and with the dynamic structural models of corporate finance where the intertemporal macroeconomic risk is captured by aggregate leverage. ${ }^{11}$

Note that we really want to estimate models represented by expression (13). In other words, we want to estimate the models with covariances rather than with betas. We simply transform the estimates obtained from equations (24) through (27) using the following expressions:

$$
\hat{\gamma}_{m}=\frac{\hat{\lambda}_{m}}{\operatorname{Var}\left(u_{m}\right)}, \hat{\gamma}_{\text {Lev }}=\frac{\hat{\lambda}_{\text {Lev }}}{\operatorname{Var}\left(u_{\text {Lev }}\right)}, \hat{\gamma}_{\Delta c}=\frac{\hat{\lambda}_{\Delta c}}{\operatorname{Var}\left(u_{\Delta c}\right)} .
$$

From equation (13), $\hat{\gamma}_{m}=1-\hat{\theta}$ and $\hat{\gamma}_{z}=\hat{\theta} \hat{\kappa}$. Therefore,

$$
\begin{aligned}
& \hat{\theta}=1-\hat{\gamma}_{m} \\
& \hat{\kappa}=\frac{\hat{\gamma}_{z}}{1-\hat{\gamma}_{m}} \\
& \text { EIS }=\frac{1}{\hat{\kappa}} \\
& \text { Risk Aversion }=1-\hat{\theta}(1-\hat{\kappa})
\end{aligned}
$$

\footnotetext{
${ }^{11}$ See Bhamra et al. (2010 a, 2010 b).
} 
From these gamma coefficients, we finally estimate the parameters of interest, $\theta, \kappa, E I S$ and the relative risk aversion coefficient.

\section{Empirical Results}

Adrian et al. (2015) show that the time-varying excess returns on stocks and bonds are mainly explained by time-varying prices of risk. This seems to be much more relevant than changes in betas. In other words, to allow for a $\lambda_{1} \neq 0$ in equation (16) is a fundamental point in this econometric implementation. ${ }^{12}$ Using an estimation approach consistent with a dynamic asset pricing framework is not only important for testing asset pricing models in general, but also for the estimation of preference parameters, which reflects aversion over time and across states. This is a key difference between the estimation procedure employed in this research to estimate the EIS and previous papers in literature. Moreover, the behavior of the market price of risk of leverage, non-durable consumption, stockholder consumption, and surplus consumption strongly affects the estimate of the EIS. Before presenting the formal numerical results, we display in Figures 2.A and 2.B the market price of risks of leverage and the growth rate of surplus consumption denoted by $S C_{t}$. From equations (25), (26), and (33), the market prices of risk are given by the following equations:

$$
\begin{aligned}
& \hat{\lambda}_{m t}=\hat{\lambda}_{m}+\hat{\lambda}_{m, L e v} \times L_{e v} \\
& \hat{\lambda}_{z t}=\hat{\lambda}_{z}+\hat{\lambda}_{z, L e v} \times L_{e v},
\end{aligned}
$$

where $z$ is either one of the measures of consumption growth or leverage. In our specific exercise, for the case of leverage and surplus consumption as representative factor risks, the previous equations are given by

\footnotetext{
${ }^{12}$ Note that this is one of the main differences of this approach with respect to the Fama \& MacBeth (1973) procedure.
} 


$$
\begin{gathered}
M P R_{L e v, t}=\hat{\lambda}_{L e v}+\hat{\lambda}_{L e v, L e v} \times L e v_{t} \\
M P R_{s c, t}=\hat{\lambda}_{s c}+\hat{\lambda}_{s c, L e v} \times S C_{t}
\end{gathered}
$$

The leverage price of risk is mostly positive with large volatility and sharp declines after recessions. It also presents very strong positive jumps before or at the beginning of recessions. On the other hand, the surplus consumption price of risk, although volatile, it remains most of the time negative with relatively large positive increases only at the beginning or during the peak of recessions. ${ }^{13}$ However, the magnitudes of these jumps are much lower than the sharp positive jumps of the leverage market price of risk. As we see next, the behavior of these market prices of risk seem to have very relevant implications for the estimation of the EIS.

Panel A of Table 2.A shows the average risk premia for non-durable consumption growth, and the market portfolio return, while Panel B displays the estimated coefficients of non-durable consumption and the market on lagged financial intermediary leverage, which plays the role of the predicting variable. The corresponding $p$-values are reported in parentheses and the last column provides the mean absolute pricing error of each cross-sectional equation. The $p$-values are based on standard errors proposed by Kan et al. (2013). They provide standard errors of risk premium estimators adjusted for the errors-in-variable and model misspecification. ${ }^{14}$ Not that the estimates shown in Panels A and B are obtained using betas as explanatory variables. Panel $\mathrm{C}$ shows the risk premia when we transform the estimated coefficients with expression (34). Finally, we report the preference parameters in Panel D of Table

\footnotetext{
${ }^{13}$ The market prices of risk of non-durable consumption and stockholder consumption closely follow the time-varying behavior of surplus consumption. However, they are much less volatile and negative in most quarters. Neither presents high positive peaks at the beginning of recessions. This already suggests that models with consumption data cannot explain asset price data.

${ }^{14}$ The details of the Kan et al. (2013) econometric methodology applied to the two-pass cross-sectional regression with rolling estimators as in this paper, and the corresponding expressions for the standard errors of the risk premia adjusted by errors-in-variable and model misspecification, can be found in González-Urteaga \& Rubio (2016).
} 
2.A, where $\hat{\theta} \equiv(1-\hat{\gamma}) /(1-\hat{\kappa})$ and $\hat{\kappa}=1 / \hat{\psi}$ is the inverse of the EIS. The $p$-values of preference parameters are obtained from standard errors estimated by the Delta method.

The empirical performance of the model is extremely poor. The estimates of both risk aversion and the EIS are negative, although they are not statistically different from zero. This result implies that the results do not have a sensible economic interpretation. One may think that this is due to the use of non-durable consumption, which presents the typical very smooth behavior. Unfortunately, Tables 2.B and 2.C show similar economic results when we employ stockholder consumption and surplus consumption, respectively. Surprisingly, when we employ stockholder consumption, the estimates of the EIS and risk aversion are not only negative, but they are significantly different from zero. Surplus consumption shows again negative estimates but they are not significantly different from zero. Overall, consumption data do not seem to capture the dynamics of the market price of risk of aggregate consumption. The implicit preference parameters do not seem to have a reasonable economic interpretation.

Table 2.D shows the results using leverage as both the risk factor and the predicting variable. The results are now very different, and they also have a potentially interesting economic interpretation. The market risk premium remains negative and significantly different from zero. However, the average leverage risk premium is equal to 0.029 and seems to be estimated with precision. The coefficient of the price of leverage risk on lagged intermediary leverage is equal to 0.122 and is significantly different from zero. More importantly, the estimates of the EIS and risk aversion are 0.943 and 1.094, respectively. Both estimates are statistically different from zero. The risk aversion coefficient is slightly higher than the EIS suggesting preference for early resolution of uncertainty. 
The evidence seems to be favorable to the use of leverage as a proxy for the marginal utility of wealth of financial intermediaries. In any case, we must recognize that other authors also find a reasonable matching between consumption and stock return series, and an estimate of the EIS close to one as in our paper. Vissing-Jorgensen (2002) finds similar results for bondholders within the limited participation framework, \& Mulligan (2002) also obtains EIS estimates around one by analyzing the relation between consumption growth and the after-tax capital rental rate. This implies that the leverage variable is not a necessary condition to obtain a positive, close to one, and significant EIS estimate. However, we believe that the evidence reported in this paper do show that marginal utility of wealth should play a much more prominent role to explain the time-varying behavior of expected returns and the corresponding magnitude of preference parameters.

In the context of macro-finance models, Hansen \& Jagannathan (1991) show that the volatility of the SDF that satisfies the first order condition of the intertemporal consumption/investment model must exceed the Hansen-Jagannathan bound given by

$$
\operatorname{Var}(M) \geq\left(1_{N}-E(M) E(R)\right)^{\prime} V^{-1}\left(1_{N}-E(M) E(R)\right),
$$

where $l_{N}$ is an $N$-vector of ones, $E(M)$ is the inverse of the risk-free rate, $V$ is the variance-covariance matrix of stock returns, and $E(R)$ is an $N$-vector of expected returns. We use this bound to illustrate how the recursive-preference model with leverage performs relative to the same model with the alternative measures of consumption employed in the evidence above. Given the estimates of the preference parameters of each of the four models reported in Table 2, we check whether the implied SDF consistent with each of the four alternative versions satisfy the bound for the case in which we invest in the market portfolio return and a riskless bond. In other words, given the estimates of preference parameters, the SDF given by equation (4), an 
opportunity set with one risky asset (the market portfolio) and one risk-free bond, and a subjective preference discount factor of 0.97 , we estimate the time series of the four alternative SDF with non-durable consumption, stockholder consumption, surplus consumption, and leverage.

Panel A of Table 3 shows the mean and volatility of the implied SDF when we impose on each model the estimated preference parameters. In Panel B of Table 3 we report both the mean and volatility of the SDF but we now impose the economically sensible preference parameters estimated with leverage to all four cases. In Panel A, the volatilities of the SDF estimated for non-durable consumption and surplus consumption are very low. The volatility of the SDF when we employ stockholder consumption is higher and equal to 0.24. However, the resulting mean of the SDF is higher than one. The mean and volatility of the implied SDF estimated with recursive preferences and leverage are 0.985 and 0.361 , respectively. Panel B of Table 3 shows that when we impose the same preference parameters, the volatilities of the SDF estimated with consumption data are even lower than in Panel A. The results suggest that the model with leverage growth generates an economically plausible mean and volatility of the implicit SDF. Figure 3 displays the time-varying behavior of the SDF with leverage. The implicit SDF tends to go up before and during recessions, showing a very large peak during the Great Recession. Finally, Figures 4.A and 4.B show that the only SDF that satisfies the Hansen-Jagannathan volatility bound is the one estimated with leverage. This is the case independently of the preference parameters used for the three alternative measures of consumption growth. These additional empirical results suggest that the model with leverage growth performs relatively well relative to the model with consumption data, which implies that the estimation of the EIS with leverage is trustable. 


\section{Conclusions}

The evidence reported in this paper confirms the importance of using data of financial intermediaries to understand the time-series and cross-sectional behavior of equity returns. Note that funding constraints are always binding, and leverage is a reasonable measure of these constraints. As pointed out by Adrian et al. (2014), this implies that leverage measures the marginal utility of wealth of financial intermediaries, which are big players in stock markets. The SDF in which bad times are defined in terms of high marginal value of wealth of financial intermediaries captures the timevarying and counter-cyclical behavior of the SDF and expected returns. This seems to have relevant consequences for the estimation of the EIS. Under this framework, and using a dynamic asset pricing estimation methodology, the estimated EIS is equal to 0.943 . 


\section{References}

Adrian, T., R. Crump, \& E. Moench (2015). Regression-Based Estimation of Dynamic Asset Pricing Models. Journal of Financial Economics, 118, 211-244.

Adrian, T., E. Etula, \& T. Muir (2014). Financial Intermediaries and the Cross-Section of Asset Returns. Journal of Finance, 69, 2557-2596.

Adrian, T., E. Moench, \& H. Song Shin (2014). Dynamic Leverage Asset Pricing. Federal Reserve Bank of New York Staff Reports.

Asness, C., A. Frazzini, \& L. Pedersen (2014). Quality Minus Junk. Working Paper, AQR Capital Management and New York University, Stern School of Business.

Bhamra, H., L. Kuehn, \& I. Strebulaev (2010 a). The Levered Equity Risk Premium and Credit Spreads: A Unified Framework. Review of Financial Studies, 23, 645-703.

Bhamra, H., L. Kuehn, \& I. Strebulaev (2010 b). The Aggregate Dynamics of Capital Structure and Macroeconomic Risk. Review of Financial Studies, 23, 645-703.

Bansal, R., \& A. Yaron (2004). Risks for the long run. Journal of Finance, 59, 14811509.

Bansal, R., D. Kiku, \& A. Yaron (2009). Empirical Evaluation of the Long-Run Risks Model for Asset Prices. Working Paper, Fuqua School of Business, Duke University.

Campbell, J. (1993). Intertemporal Asset Pricing Without Consumption Data. American Economic Review, 83, 487-512.

Campbell, J. (1996). Understanding Risk and Return. Journal of Political Economy, $104,298-345$.

Campbell, J. (2003). Consumption-Based Asset Pricing. In G. Constantinides, M. Harris, \& R. Stulz (Eds), Handbook of the Economics of Finance (1B, pp. 803-887). Elsevier. 
Campbell, J., \& J. Cochrane (1999). By force of habit: A consumption-based explanation of aggregate stock market behavior. Journal of Political Economy, 107, 205-251.

Campbell, J., \& N. Mankiw (1989). Consumption, Income, and Interest Rates: Reinterpreting the Time Series Evidence. In O. Blanchard \& S. Fischer (Eds), National Bureau of Economic Research Macroeconomics Annual (4, pp. 185-216). MIT Press.

Campbell, J., \& N. Mankiw (1991). The Response of Consumption to Income: A CrossCountry Investigation. European Economic Review, 35, 723-767.

Cochrane, J. (2007). Financial Markets and the Real Economy. In R. Mehra (Eds), Handbook of the Equity Premium (pp. 237-325). Elsevier.

Cochrane, J. (2016). The Habit Habit. Working Paper, Hoover Institution, Stanford University.

Constantinides, G., \& D. Duffie (1996). Asset Pricing with Heterogeneous Consumers. Journal of Political Economy, 104, 219-240.

Epstein, L., \& S. Zin (1989). Substitution Risk Aversion and the Temporal Behavior of Consumption and Asset Returns: A Theoretical Framework. Econometrica, 57, 937968.

Epstein, L., \& S. Zin (1991). Substitution Risk Aversion and the Temporal Behavior of Consumption and Asset Returns: An Empirical Investigation. Journal of Political Economy, 99, 555-576.

Fama, E., \& J. MacBeth (1973). Risk, Return, and Equilibrium: Empirical Tests. Journal of Political Economy, 81, 607-636. 
Garleanu, N., \& S. Panageas (2015). Young, Old, Conservative, and Bold: The Implications of Heterogeneity and Finite Lives for Asset Pricing. Journal of Political Economy, 123, 670-685.

Ghosh, A., C. Julliard, \& A. Taylor (2017). What Is Consumption-CAPM Missing? An Information-Theoretic Framework for the Analysis of asset Pricing Models. Review of Financial Studies, 30, 442-504.

Gomes, F., \& P. Ribeiro (2015). Estimating the Elasticity of Intertemporal Substitution Taking Into Account the Precautionary Savings Motive. Journal of Macroeconomics, $45,108-123$.

González-Urteaga, A., \& G. Rubio (2016). The Cross-Sectional Variation of Volatility Risk Premia. Journal of Financial Economics, 119, 353-370.

Guvenen, F. (2006). Reconciling Conflicting Evidence on the Elasticity of Intertemporal Substitution: A Macroeconomic Perspective. Journal of Monetary Economics, 53, 1451-1472.

Hansen, L., J. Heaton, \& N. Li (2008). Consumption Strikes Back?: Measuring Longrun Risk. Journal of Political Economy, 116, 260-302.

Hansen, L., \& R. Jagannathan (1991). Restrictions on Intertemporal Marginal Rates of Substitution Implied by Asset Returns. Journal of Political Economy, 99, 225-262.

Hansen, L., \& K. Singleton (1983). Stochastic Consumption, Risk Aversion, and the Temporal Behavior of Asset Returns. Journal of Political Economy, 91, 249-265.

Kan, R., C. Robotti, \& J. Shanken (2013). Pricing Model Performance and the TwoPass Cross-Sectional Regression Methodology. Journal of Finance, 68, 2617-2649.

Kreps, D., \& E. Porteus (1978). Temporal Resolution of Uncertainty and Dynamic Choice Theory. Econometrica, 46, 185-200. 
Malloy, C., T. Moskowitz, \& A. Vissing-Jorgensen (2011). Long-run stockholder consumption risk and asset returns. Journal of Finance, 64, 2427-2479.

Muir, T. (2014). Financial Crisis and Risk Premia. Working Paper, Yale School of Management, Department of Finance.

Mulligan, C. (2002). Capital, Interest, and Aggregate Intertemporal Substitution. Working Paper, National Bureau of Economic Research 9373.

Ogaki, M., \& C. Reinhart (1998). Measuring Intertemporal Substitution: The Role of Durable Goods. Journal of Political Economy, 106, 1078-1098.

Vissing-Jorgensen, A. (2002). Limited Asset Market Participation and Intertemporal Substitution. Journal of Political Economy, 110, 825-853.

Vissing-Jorgensen, A., \& O. Attanasio (2003). Stock Market Participation, Intertemporal Substitution and Risk Aversion. American Economic Review, AEA Papers \& Proceedings, 93, 383-391.

Yogo, M. (2004). Estimating the Elasticity of Intertemporal Substitution when Instruments are Weak. Review of Economics and Statistics, 86, 797-810. 
Table 1

Descriptive Statistics of Aggregate Variables: Growth of Non-Durable Consumption, Stockholder Consumption, Surplus Consumption, Leverage, and the Market Portfolio Return. Quarterly Real Data from January 1968 to December 2009

\begin{tabular}{|c|c|c|c|c|c|c|c|}
\hline & $\begin{array}{l}\text { Non-Durable } \\
\text { Consumption }\end{array}$ & $\begin{array}{c}\text { Stockholder } \\
\text { Consumption }\end{array}$ & $\begin{array}{c}\text { Surplus } \\
\text { Consumption }\end{array}$ & $\begin{array}{c}\text { Leverage } \\
\text { Financial } \\
\text { Intermediaries }\end{array}$ & $\begin{array}{l}\text { Stock Market } \\
\text { Return }\end{array}$ & $\begin{array}{l}\text { Annualized } \\
\text { Average } \\
\text { Growth } \\
\end{array}$ & $\begin{array}{l}\text { Annualized } \\
\text { Volatility }\end{array}$ \\
\hline $\begin{array}{l}\text { Non-Durable } \\
\text { Consumption }\end{array}$ & 1 & 0.253 & 0.931 & 0.088 & 0.341 & 0.0194 & 0.0118 \\
\hline $\begin{array}{l}\text { Stockholder } \\
\text { Consumption }\end{array}$ & & 1 & 0.272 & 0.256 & 0.780 & 0.0332 & 0.0428 \\
\hline $\begin{array}{c}\text { Surplus } \\
\text { Consumption }\end{array}$ & & & 1 & 0.113 & 0.342 & -0.0250 & 0.0556 \\
\hline $\begin{array}{c}\text { Leverage } \\
\text { Financial } \\
\text { Intermediaries }\end{array}$ & & & & 1 & 0.135 & 0.0424 & 0.2696 \\
\hline $\begin{array}{l}\text { Stock Market } \\
\text { Return }\end{array}$ & & & & & 1 & 0.0621 & 0.1815 \\
\hline
\end{tabular}


Table 2.A

Estimating the Elasticity of Intertemporal Substitution with Non-Durable Consumption Growth under a Dynamic Asset Pricing Framework

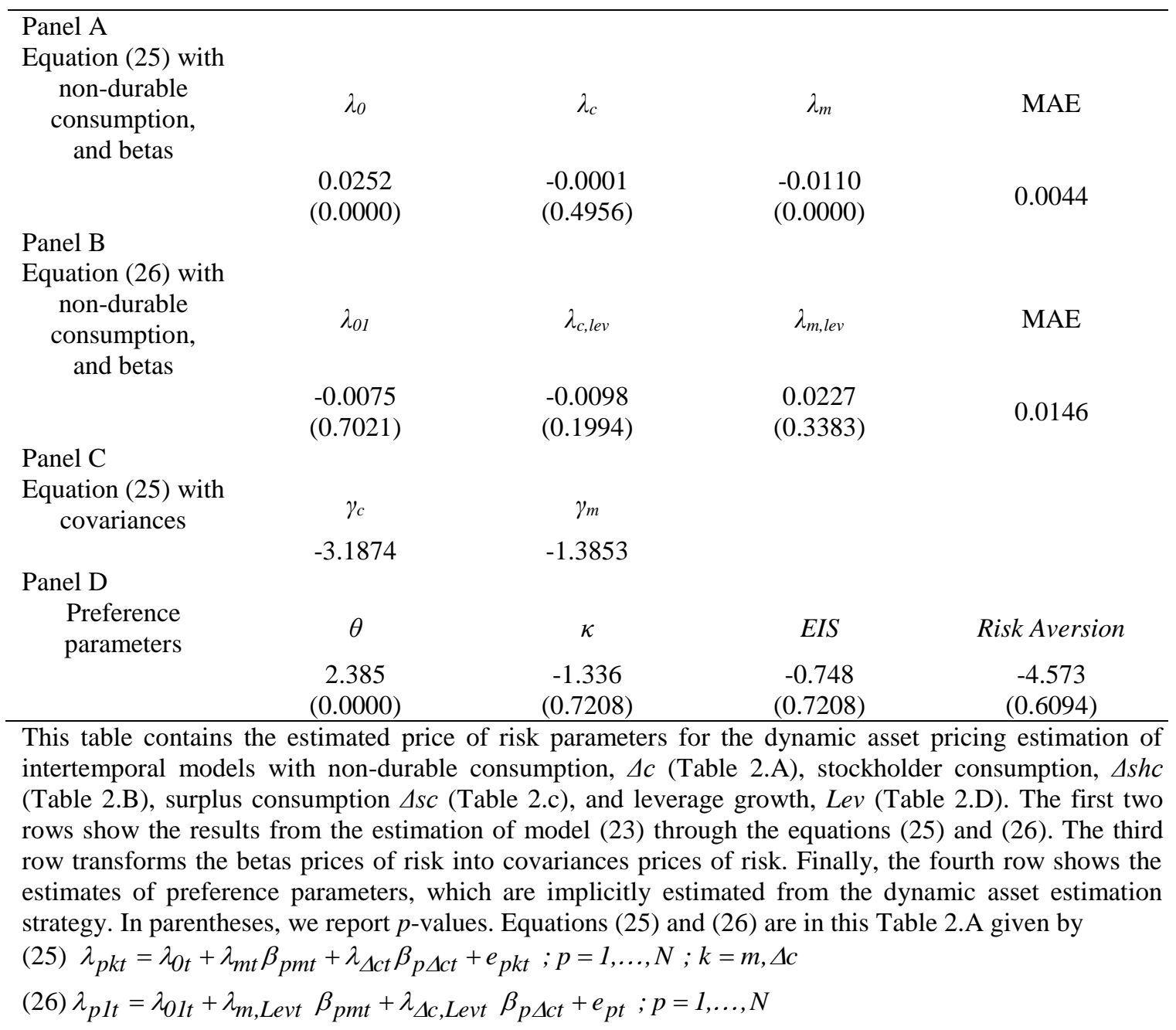


Table 2.B

Estimating the Elasticity of Intertemporal Substitution with Stockholder Consumption Growth under a Dynamic Asset Pricing Framework

\begin{tabular}{|c|c|c|c|c|}
\hline Panel A & & & & \\
\hline $\begin{array}{c}\text { Equation (25) with } \\
\text { stockholder } \\
\text { consumption, }\end{array}$ & $\lambda_{0}$ & $\lambda_{s h c}$ & $\lambda_{m}$ & MAE \\
\hline & $\begin{array}{c}0.0278 \\
(0.0000)\end{array}$ & $\begin{array}{l}-0.0017 \\
(0.0000)\end{array}$ & $\begin{array}{l}-0.0147 \\
(0.0000)\end{array}$ & 0.0036 \\
\hline Panel B & & & & \\
\hline $\begin{array}{c}\text { Equation (26) with } \\
\text { stockholder } \\
\text { consumption, }\end{array}$ & $\lambda_{01}$ & $\lambda_{s h c, l e v}$ & $\lambda_{m, l e v}$ & MAE \\
\hline & $\begin{array}{l}-0.0323 \\
(0.0067)\end{array}$ & $\begin{array}{c}0.0032 \\
(0.1142)\end{array}$ & $\begin{array}{c}0.0094 \\
(0.3923)\end{array}$ & 0.0128 \\
\hline Panel C & & & & \\
\hline $\begin{array}{l}\text { Equation (25) with } \\
\text { covariances }\end{array}$ & $\gamma_{s h c}$ & $\gamma_{m}$ & & \\
\hline & -3.9582 & -1.9658 & & \\
\hline Panel D & & & & \\
\hline $\begin{array}{l}\text { Preference } \\
\text { parameters }\end{array}$ & $\theta$ & $\kappa$ & $E I S$ & Risk Aversion \\
\hline & $\begin{array}{c}2.966 \\
(0.0000)\end{array}$ & $\begin{array}{c}-1.335 \\
(0.0007)\end{array}$ & $\begin{array}{c}-0.749 \\
(0.0007)\end{array}$ & $\begin{array}{c}-5.924 \\
(0.0000)\end{array}$ \\
\hline
\end{tabular}

See the note in Table 2.A. Equations (25) and (26) are in this Table 2.B given by

(25) $\lambda_{p k t}=\lambda_{0 t}+\lambda_{m t} \beta_{p m t}+\lambda_{\Delta s h c t} \beta_{p \Delta s h c t}+e_{p k t} ; p=1, \ldots, N ; k=m, \Delta s h c$

(26) $\lambda_{p l t}=\lambda_{01 t}+\lambda_{m, \text { Levt }} \beta_{\text {pmt }}+\lambda_{\Delta s h c, \text { Levt }} \beta_{p \Delta s h c t}+e_{p t} ; p=1, \ldots, N$ 
Table 2.C

Estimating the Elasticity of Intertemporal Substitution with Surplus Consumption Growth under a Dynamic Asset Pricing Framework

\begin{tabular}{|c|c|c|c|c|}
\hline Panel A & & & & \\
\hline $\begin{array}{c}\text { Equation (25) with } \\
\text { surplus } \\
\text { consumption, }\end{array}$ & $\lambda_{0}$ & $\lambda_{s c}$ & $\lambda_{m}$ & MAE \\
\hline & $\begin{array}{c}0.0239 \\
(0.0000)\end{array}$ & $\begin{array}{l}-0.0015 \\
(0.0099)\end{array}$ & $\begin{array}{l}-0.0095 \\
(0.0000)\end{array}$ & 0.0044 \\
\hline Panel B & & & & \\
\hline $\begin{array}{c}\text { Equation (26) with } \\
\text { surplus } \\
\text { consumption, }\end{array}$ & $\lambda_{01}$ & $\lambda_{s c, l e v}$ & $\lambda_{m, l e v}$ & MAE \\
\hline & $\begin{array}{l}-0.0076 \\
(0.7040)\end{array}$ & $\begin{array}{l}-0.0353 \\
(0.1495)\end{array}$ & $\begin{array}{c}0.0232 \\
(0.2678)\end{array}$ & 0.0149 \\
\hline Panel C & & & & \\
\hline $\begin{array}{l}\text { Equation }(25) \text { with } \\
\text { covariances }\end{array}$ & $\begin{array}{c}\gamma_{s c} \\
-2.4498\end{array}$ & $\begin{array}{c}\gamma_{m} \\
-1.1943\end{array}$ & & \\
\hline $\begin{array}{l}\text { Panel D } \\
\text { Preference } \\
\text { parameters }\end{array}$ & $\theta$ & $\kappa$ & $E I S$ & Risk Aversion \\
\hline & $\begin{array}{c}2.194 \\
(0.0000)\end{array}$ & $\begin{array}{c}-1.116 \\
(0.1020)\end{array}$ & $\begin{array}{c}-0.896 \\
(0.1020)\end{array}$ & $\begin{array}{c}-3.644 \\
(0.0231)\end{array}$ \\
\hline
\end{tabular}

See the note in Table 2.A. Equations (25) and (26) are in this Table 2.C given by

(25) $\lambda_{p k t}=\lambda_{0 t}+\lambda_{m t} \beta_{p m t}+\lambda_{\Delta s c t} \beta_{p \Delta s c t}+e_{p k t} ; p=1, \ldots, N ; k=m, \Delta s c$

(26) $\lambda_{p l t}=\lambda_{01 t}+\lambda_{m, \text { Levt }} \beta_{p m t}+\lambda_{\Delta s c, \text { Levt }} \beta_{p \Delta s c t}+e_{p t} ; p=1, \ldots, N$ 
Table 2.D

Estimating the Elasticity of Intertemporal Substitution with Leverage Growth under a Dynamic Asset Pricing Framework

\begin{tabular}{|c|c|c|c|c|}
\hline Panel A & & & & \\
\hline $\begin{array}{l}\text { Equation (25) with } \\
\text { leverage growth, }\end{array}$ & $\lambda_{0}$ & $\lambda_{\text {lev }}$ & $\lambda_{m}$ & MAE \\
\hline & $\begin{array}{c}0.0183 \\
(0.0000)\end{array}$ & $\begin{array}{c}0.0293 \\
(0.0000)\end{array}$ & $\begin{array}{c}-0.0045 \\
(0.0493)\end{array}$ & 0.0036 \\
\hline Panel B & & & & \\
\hline $\begin{array}{l}\text { Equation (26) with } \\
\text { leverage growth, }\end{array}$ & $\lambda_{01}$ & $\lambda_{l e v, l e v}$ & $\lambda_{m, l e v}$ & MAE \\
\hline & $\begin{array}{l}-0.0139 \\
(0.1369)\end{array}$ & $\begin{array}{c}0.1217 \\
(0.0085)\end{array}$ & $\begin{array}{c}0.0386 \\
(0.0046)\end{array}$ & 0.0150 \\
\hline Panel C & & & & \\
\hline $\begin{array}{l}\text { Equation }(25) \text { with } \\
\text { covariances }\end{array}$ & $\begin{array}{c}\gamma_{l e v} \\
1.6556\end{array}$ & $\begin{array}{c}\gamma_{m} \\
-0.5619\end{array}$ & & \\
\hline $\begin{array}{l}\text { Panel D } \\
\text { Preference } \\
\text { parameters }\end{array}$ & $\theta$ & $\kappa$ & $E I S$ & Risk Aversion \\
\hline & $\begin{array}{c}1.562 \\
(0.0000)\end{array}$ & $\begin{array}{c}1.060 \\
(0.0000)\end{array}$ & $\begin{array}{c}0.9434 \\
(0.0000)\end{array}$ & $\begin{array}{c}1.094 \\
(0.0000)\end{array}$ \\
\hline
\end{tabular}

See the note in Table 2.A. Equations (25) and (26) are in this Table 2.D given by

(25) $\lambda_{p k t}=\lambda_{0 t}+\lambda_{m t} \beta_{p m t}+\lambda_{\text {Levt }} \beta_{p L e v t}+e_{p k t} ; p=1, \ldots, N ; k=m$, Lev

(26) $\lambda_{p l t}=\lambda_{01 t}+\lambda_{m, \text { Levt }} \beta_{\text {pmt }}+\lambda_{\text {Lev }, \text { Levt }} \beta_{\text {pLevt }}+e_{p t} ; p=1, \ldots, N$ 
Table 3

Implicit Stochastic Discount Factor Statistics for the Growth of Non-Durable Consumption, Stockholder Consumption, Surplus Consumption, and Leverage. Quarterly Data from January 1968 to December 2009

\begin{tabular}{|c|c|c|c|c|}
\hline $\begin{array}{c}\text { Panel A: } \\
\text { SDF (with specific } \\
\text { preference parameters) }\end{array}$ & $\begin{array}{l}\text { Non-Durable } \\
\text { Consumption }\end{array}$ & $\begin{array}{l}\text { Stockholder } \\
\text { Consumption }\end{array}$ & $\begin{array}{c}\text { Surplus } \\
\text { Consumption }\end{array}$ & $\begin{array}{c}\text { Leverage } \\
\text { Financial } \\
\text { Intermediaries }\end{array}$ \\
\hline Mean SDF & 0.982 & 1.015 & 0.955 & 0.985 \\
\hline Volatility SDF & 0.124 & 0.240 & 0.132 & 0.361 \\
\hline $\begin{array}{c}\text { Panel B: } \\
\text { SDF (with preference } \\
\text { parameters for Leverage) }\end{array}$ & $\begin{array}{l}\text { Non-Durable } \\
\text { Consumption }\end{array}$ & $\begin{array}{l}\text { Stockholder } \\
\text { Consumption }\end{array}$ & $\begin{array}{c}\text { Surplus } \\
\text { Consumption }\end{array}$ & $\begin{array}{c}\text { Leverage } \\
\text { Financial } \\
\text { Intermediaries }\end{array}$ \\
\hline Mean SDF & 0.959 & 0.953 & 0.978 & 0.985 \\
\hline Volatility SDF & 0.046 & 0.030 & 0.056 & 0.361 \\
\hline \multicolumn{5}{|c|}{$\begin{array}{l}\text { This table shows the mean and volatilities of the implicit stochastic discount factor with recursive } \\
\text { preferences given by expression (4), when we use the estimates of the preference parameters obtained } \\
\text { from the dynamic asset pricing estimation of the linear version the model. We use three alternative } \\
\text { measures of consumption growth, including non-durable consumption, stockholder consumption, and } \\
\text { surplus consumption from the external habit-based preference model. Moreover, we employ the leverage } \\
\text { growth financial intermediaries, and the value-weighted market portfolio return. }\end{array}$} \\
\hline
\end{tabular}


Figure 1

Annual Growth Real Rates of the Leverage Factor, Non-Durable Consumption, Stockholder Consumption, and Surplus Consumption: 1968-2009

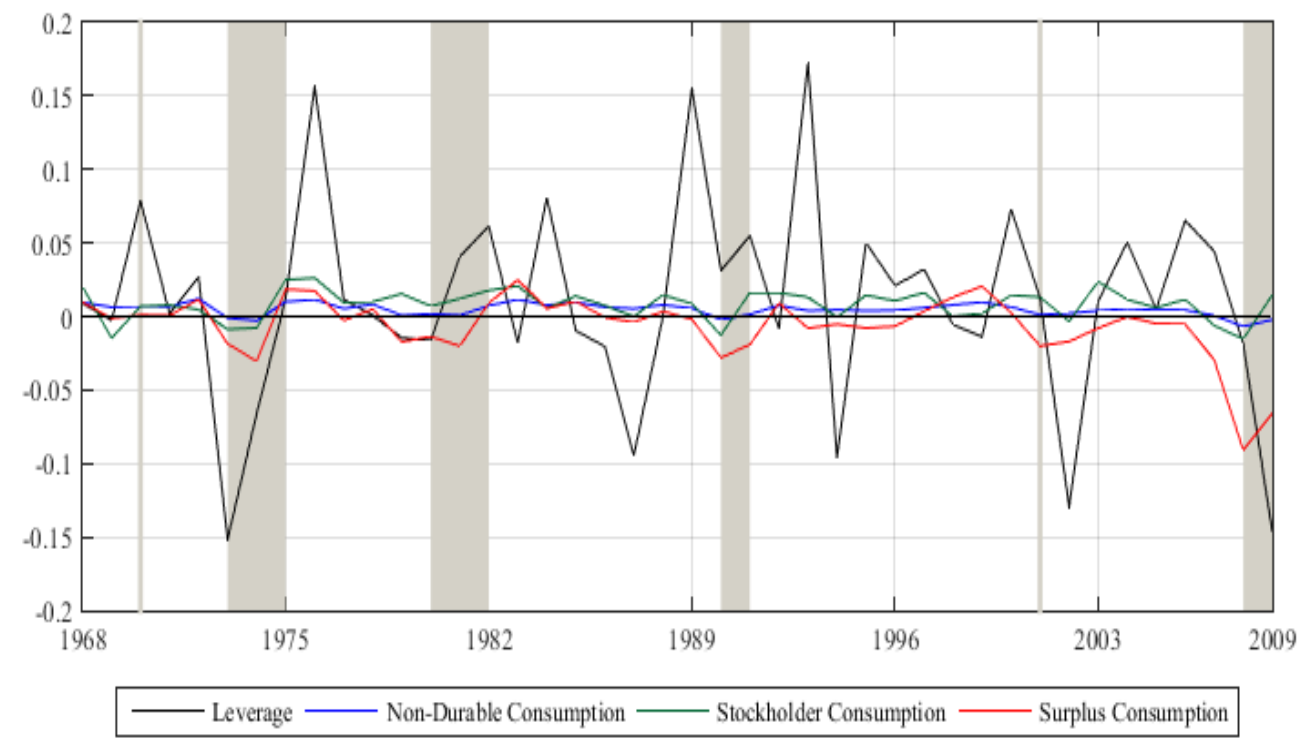


Figure 2.A

Time-Varying Behavior of the Price of Leverage Risk in Percentage Annualized Terms: 1968-2009

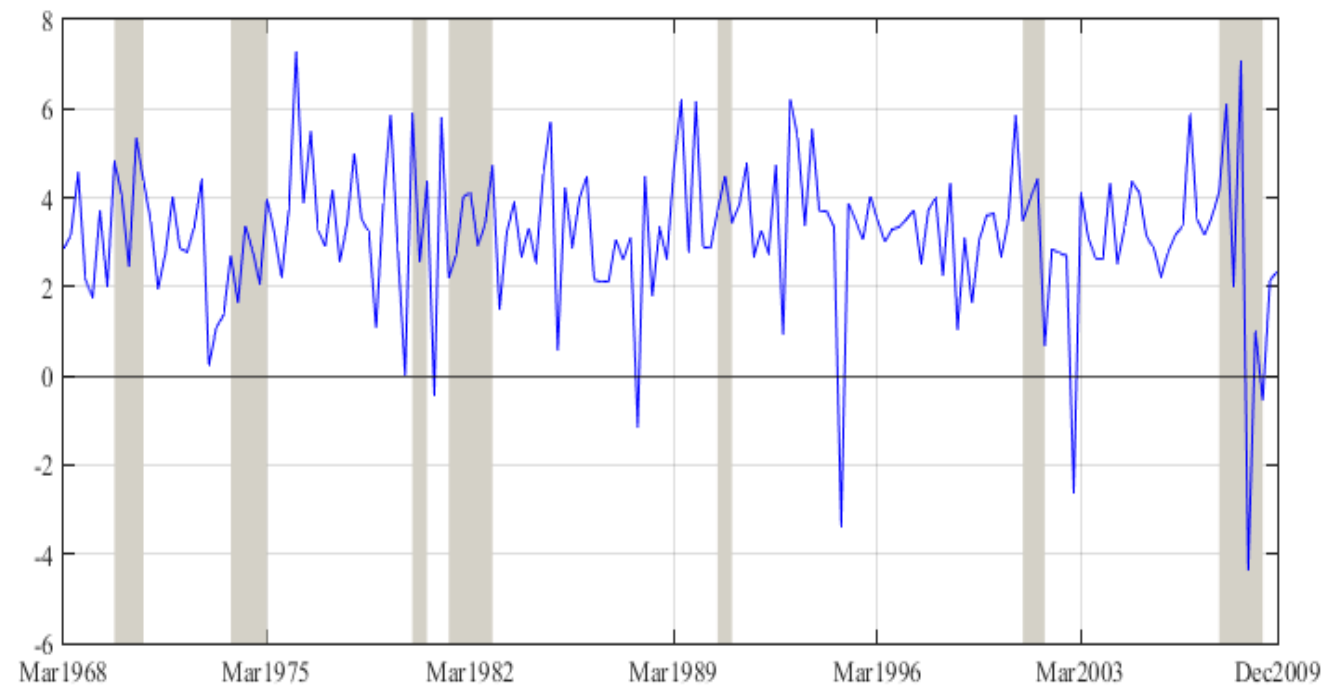

Figure 2.B

Time-Varying Behavior of the Price of Surplus Consumption Risk in Percentage Annualized Terms: 1968-2009

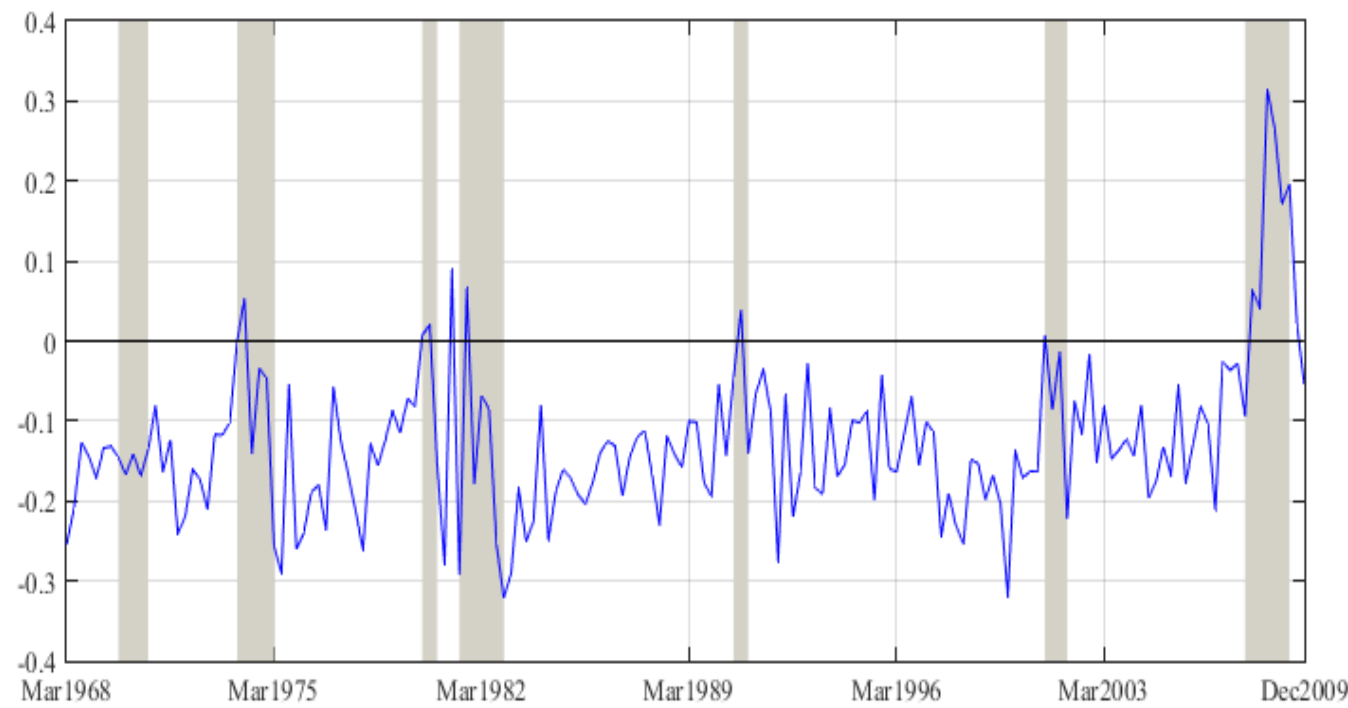


Figure 3

The Implicit Stochastic Discount Factor with Recursive Preferences, the Market Portfolio Return, and Leverage Growth of Financial Intermediaries. Data from January 1968 to December 2009

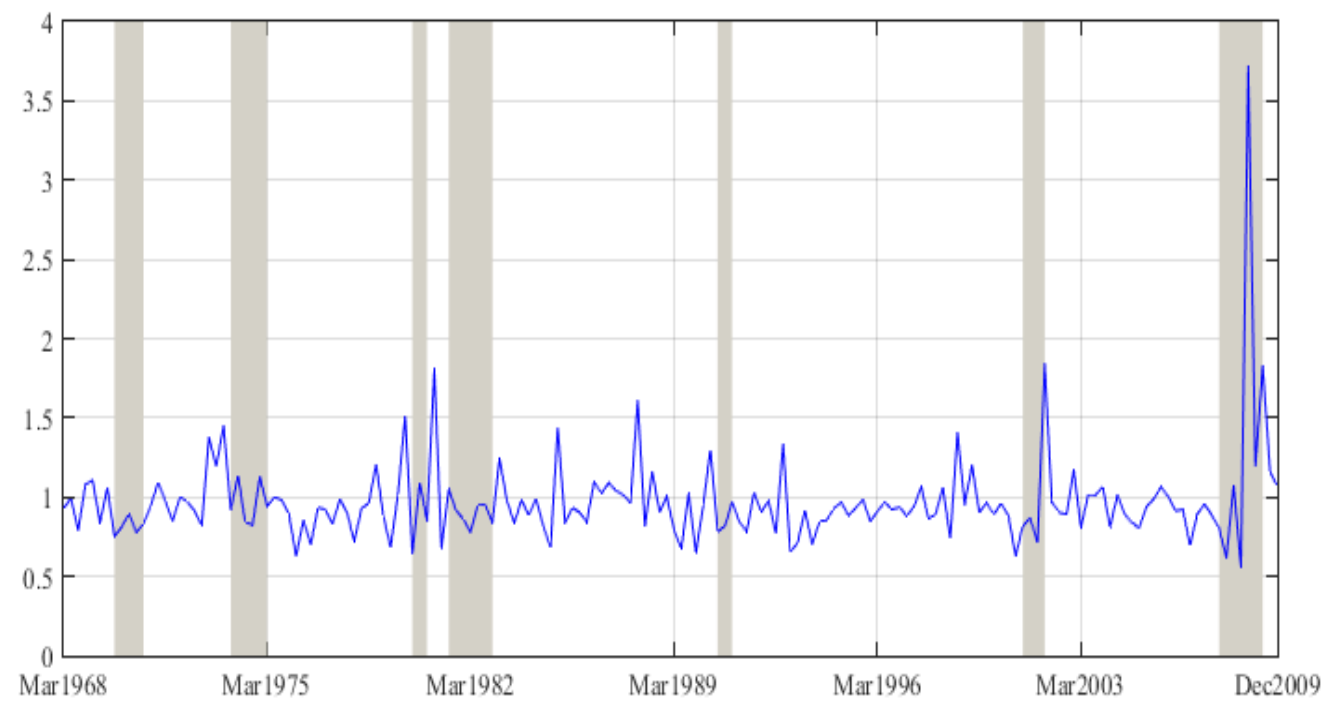




\section{Figure 4.A}

The Hansen-Jagannathan volatility bound for the market portfolio return and three-month Treasury bills as test assets, and preference parameters estimated for each state variable: non-durable consumption, stockholder consumption, surplus consumption, and the leverage growth of financial intermediaries. Quarterly Data from January 1968 to December 2009

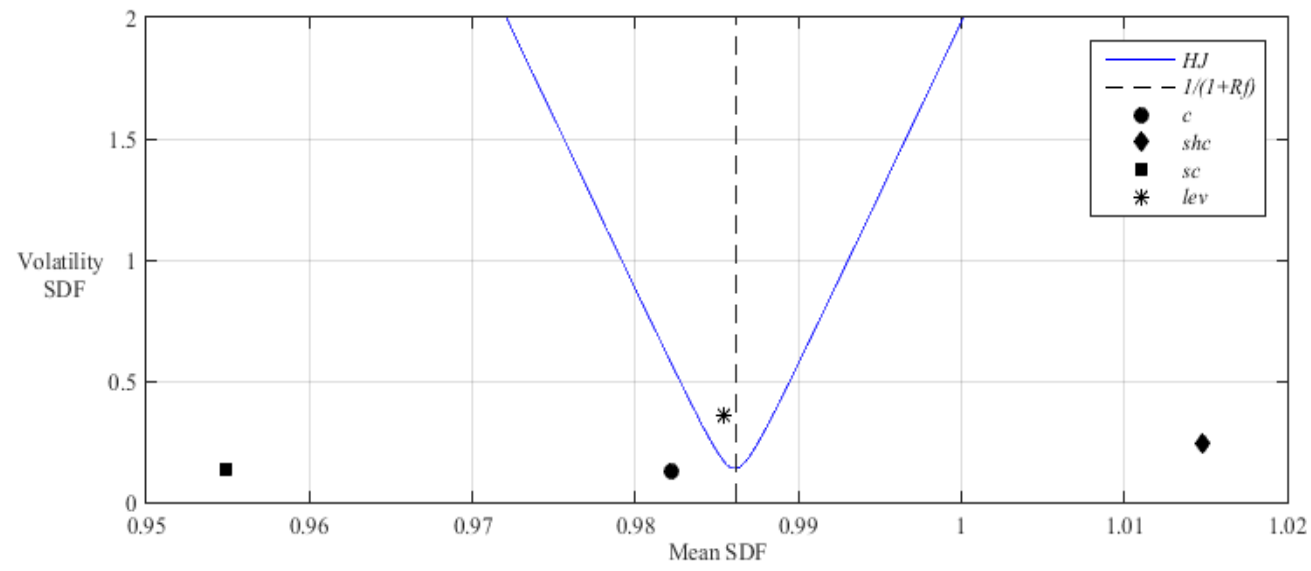

\section{Figure 4.B}

The Hansen-Jagannathan volatility bound for the market portfolio return and three-month Treasury bills as test assets, and preference parameters estimated from the leverage growth of financial intermediaries. Quarterly Data from January 1968 to December 2009

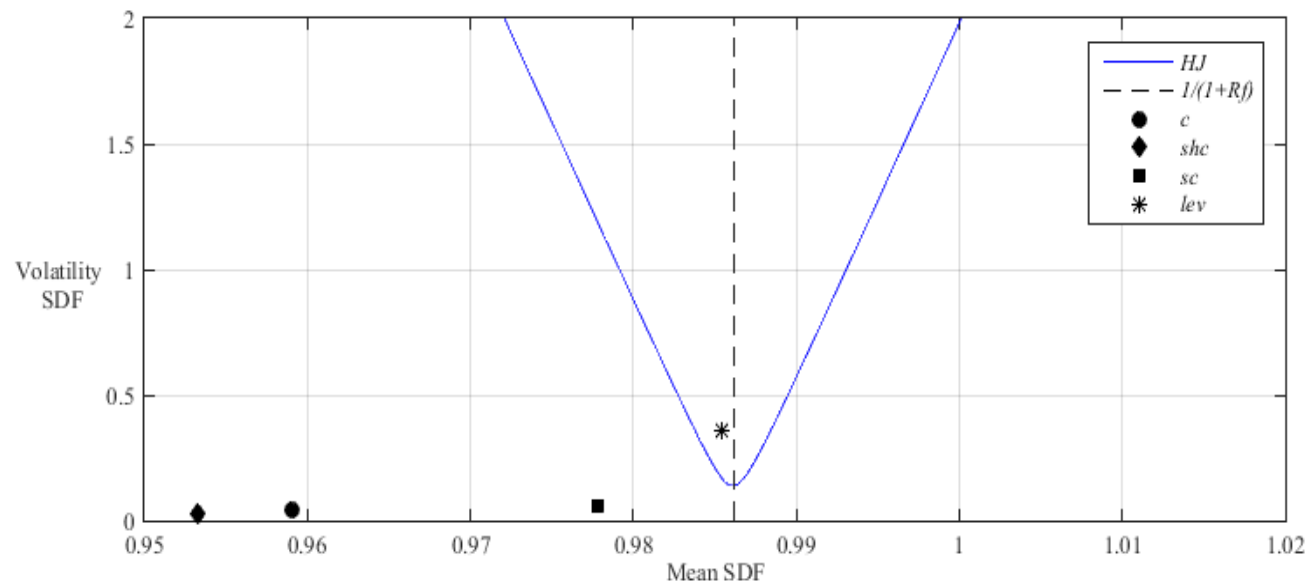

